\title{
PRODUÇÃo DISCENTE
}

O ESTADO DEMOCRÁTICO DE DIREITO E OS DIREITOS FUNDAMENTAIS SOCIAIS NA CONSTITUIÇÃO BRASILEIRA DE 1988

Recebimento do artigo: 13/07/2007

Aprovado em: 30/08/2007

\section{Vera Lúcia Resende \\ Orientadora: Adriana Zawada Melo}

\section{Sumário}

1 Introdução. 2 O Estado Democrático de Direito e a Dignidade da Pessoa Humana. 3 A Incorporação dos Direitos Sociais na Cultura Constitucional Contemporânea. 4 Direitos Fundamentais e sua classificação. 5 Os direitos fundamentais sociais na Constituição brasileira de 1988. 6 Considerações finais. 7 Referências Bibliográficas.

\section{Resumo}

O presente trabalho tem como objetivo demonstrar que a Constituição brasileira de 1988 avançou, entre outros temas, com os direitos sociais. Mostra que esses direitos se baseiam nas necessidades humanas fundamentais e que devem ser respeitados, bem como protegidos e efetivados.

\begin{abstract}
The present work has as objective among others to demonstrate that the Brazilian Constitution of 1988 advanced, among others subjetcs, with the social rigths. It shows that these rigths are based on the necessities basic human beings and must be respected, as well as protected and accomplished.
\end{abstract}

\section{Palavras-chaves}

\section{Key words}

Constituição. Direitos Fundamentais. Dignidade da pessoa humana. Direitos Sociais. 


\section{Introdução}

A dignidade da pessoa humana é uma idéia, cuja normatização recente remonta a longo percurso histórico de lutas e de conquistas sociais. A conscientização paulatina e demorada da necessidade de se proteger a liberdade e as demais expressões e manifestações da condição humana é um processo lento que encontra acolhimento na legislação mais recente, seja no plano internacional, seja no plano nacional. A dignidade da pessoa humana, como princípio orientador do discurso jurídico-internacional, assim como os direitos fundamentais, representam ambos uma sólida conquista da humanidade, cuja história não se pode olvidar. Seus ecos na Constituição Federal de 1988 não podem, da mesma forma, ser apagados.

A Constituição de 1988, com o Estado Democrático de Direito, inaugurou um novo período no constitucionalismo brasileiro. Avançou, entre outros temas, com os direitos fundamentais sociais, que já vinham se destacando no constitucionalismo alienígena. Assumiu, nossa Carta Magna, como valores essenciais de uma sociedade, os direitos sociais que buscam igualdade material, assumindo relevo quanto a oportunidades e a reais condições de vida a todos, indistintamente.

\section{O Estado Democrático de Direito e a Dignidade da Pessoa Humana}

A idéia moderna de Estado Democrático, conforme nos ensina Dalmo de Abreu Dallari, tem suas raízes no século XVIII, originando a afirmação de certos valores fundamentais da pessoa como também a organização e o funcionamento do Estado, visando à proteção daqueles valores. No século XIX e na primeira metade do século $\mathrm{XX}$, não foram mais do que tentativas de realizar as aspirações do século XVIII, sendo esse ponto de partida indispensável para a compreensão dos conflitos sobre os objetivos do Estado e a participação popular. ${ }^{1}$

Foi por meio de três grandes movimentos político-sociais que ocorreu a transposição, do plano teórico para o prático, dos princípios que iriam conduzir ao Estado Democrático. O primeiro denominou-se Revolução Inglesa, cuja expressão mais significativa foi a Bill of Rights, de 1689; o segundo foi a Revolução Americana, cujos princípios foram expressos na Declaração de Independência das treze colônias americanas, em 1776; e o terceiro foi a Revolução Francesa, cujos princípios foram expressos na Declaração dos Direitos do Homem e do Cidadão, de 1789, adquirindo universalidade.

\footnotetext{
${ }^{1}$ DALLARI, Dalmo de Abreu. Elementos de Teoria Geral do Estado, 2003, p.145. 
Foram esses movimentos que determinaram as diretrizes para a organização do Estado e consolidaram a idéia de Estado Democrático de Direito como ideal supremo.

Representando o marco jurídico da transição da ditadura para o regime democrático, a Constituição de 1988, desde o seu Preâmbulo, enfatiza seu compromisso de instituir um Estado Democrático de Direito, destinado a assegurar o exercício dos direitos sociais e individuais, a liberdade, a segurança, o bem-estar, o desenvolvimento, a igualdade e a justiça como valores supremos de uma sociedade fraterna, pluralista e sem preconceitos, fundada na harmonia social e comprometida, na ordem interna e internacional, com a solução pacífica das controvérsias (...).

Conforme afirma José Afonso da Silva, o Estado Democrático de Direito não se funde na idéia de uma junção entre o Estado Democrático e o Estado de Direito. Consiste, na verdade, na criação de algo novo, uma idéia, que leva em conta os conceitos dos elementos que o compõem, e vai além na medida em que incorpora um componente revolucionário de transformação do status quo. Sendo assim, é de extrema importância o art. $1^{\circ}$, da nossa Carta Magna, quando dispõe que a República Federativa do Brasil constitui Estado Democrático de Direito. ${ }^{2}$

Certamente a intenção do constituinte ao referir-se ao Estado Democrático de Direito foi a de mostrar que ele não pretende que o Brasil seja regido por leis formais que violem eventualmente os princípios fundamentais da democracia. ${ }^{3}$

A Constituição brasileira traz estrutura consubstanciada num regime democrático e com objetivos direcionados para a redução das desigualdades sociais e regionais, promovendo o bem de todos (art. $3^{\circ}$ e seus incisos), ou seja, objetivos voltados à saúde, à previdência e à assistência social, à educação, à cultura, à seguridade. Atitudes que atentem contra a dignidade da pessoa humana devem ser repelidas, e nossa Constituição proclama em seu art. $3^{\circ}$ que constituem objetivos fundamentais, entre outros, a erradicação da pobreza e a redução das desigualdades sociais e regionais. É certo que se deve atuar lutando incessantemente contra situações desumanas, tais como o trabalho escravo e infantil, a insuficiência de moradia, a falta de saneamento básico, entre outras.

\footnotetext{
${ }^{2}$ SILVA, José Afonso da. Curso de Direito Constitucional Positivo, 2004, p. 119.

${ }^{3}$ FERREIRA FILHO, Manoel Gonçalves. Comentários à Constituição Brasileira de 1988, 2000, p.18. Na seqüência pontua: "Deve-se observar que, na doutrina espanhola, Estado Democrático de Direito foi expressão cunhada para significar 'socialismo na democracia', como se vê da obra de Elias Dias (Estado de derecho y sociedad democratica). Entretanto, esta orientação socialista a ser impressa ao Estado de Direito não foi sequer objeto de cogitação nos debates da constituinte. Não há dúvida alguma que a expressão 'Estado Democrático de Direito' não foi votada pelo constituinte brasileiro com a intenção de designar o socialismo na Constituição e na democracia pátria".
} 
É necessário que esses direitos sejam plenamente efetivados e respeitados, mas para isso deve a população conhecê-los. Conforme asseverou Dalmo de Abreu Dallari: “o primeiro passo para se chegar à plena proteção dos direitos é informar e conscientizar as pessoas sobre a existência de seus direitos e a necessidade e possibilidade de defendê-los". ${ }^{4}$

O Estado Democrático de Direito vem calcado não apenas na obediência, em seu âmbito de atuação, à legalidade, mas também, e principalmente, no respeito legitimado pela vontade do povo. Lastreado pela soberania popular e com o intuito de superar as dificuldades sociais e regionais, baseado na instauração de um regime democrático que realize a justiça social, nasce o Estado Democrático de Direito que, como o Estado Liberal de Direito, traz características básicas e de submissão às leis, mas busca respeitar as diferenças estruturais existentes entre as pessoas e, sobretudo, a justiça social e a participação democrática do povo em seu processo político. $^{5}$

O país deve assumir as linhas traçadas pelo Estado Democrático de Direito, tornando-se oportuno salientar a importância da efetividade dos direitos sociais constitucionalizados, cujo objetivo funda-se na concretização de melhores condições de vida do povo e dos trabalhadores.

Os direitos sociais, ao serem relacionados como valores supremos do Estado Democrático de Direito, pertencem à mesma categoria hierárquica dos direitos civis e políticos. Para que o Estado Democrático de Direito cumpra na sociedade o papel a que se dispõe, faz-se necessário que os preceitos constitucionais e legais se constituam não só em garantias constantes do ordenamento jurídico constitucional mas, sobretudo, na defesa dos direitos da sociedade como um todo.

A República Federativa do Brasil elege em seu artigo 1º, os fundamentos que alicerçam o Estado Democrático de Direito Brasileiro. Entre eles, o inciso III trata da dignidade da pessoa humana. Há, hoje em dia, vários significados que se podem atribuir à noção de dignidade da pessoa humana. Aduz Fábio Konder Comparato ${ }^{6}$ que a resposta à indagação sobre no que consiste a dignidade humana foi dada, sucessivamente, no campo da religião, da filosofia e da ciência.

No pensamento filosófico e político da antiguidade clássica, o que chamamos de dignidade humana estava relacionado à posição social que a pessoa ocupava entre os demais membros da comunidade. Admitia-se, então, a valoração dessa dignidade.

\footnotetext{
${ }^{4}$ DALLARI, Dalmo de Abreu. Direitos Humanos e Cidadania, 1982, p. 69.

${ }^{5}$ SILVA, José Afonso da. Curso de Direito Constitucional Positivo, 2004, p. 121.

${ }^{6}$ COMPARATO, Fábio Konder. A Afirmação histórica dos Direitos Humanos, 2004, p.1. 
No pensamento estóico, a dignidade era tida como qualidade inerente ao homem e, por isso, o distinguia das demais criaturas, no sentido de que todos os seres humanos são dotados da mesma dignidade. Fábio Konder Comparato ensina que "o estoicismo organizou-se em torno de algumas idéias centrais como a unidade moral do ser humano e a dignidade do homem, considerado filho de Zeus e possuidor, em conseqüência, de direitos inatos e iguais em todas as partes do mundo, não obstante as inúmeras diferenças individuais e grupais."”

No pensamento medieval, chegou-se à noção de que a dignidade encontra seu fundamento no fato de o ser humano ter sido feito à imagem e semelhança de Deus, mas com capacidade de autodeterminação inerente à natureza humana.

Giovanni Pico Della Mirandola, em importante obra, coloca o homem e sua dignidade em local privilegiado pelo uso da vontade e do livre consentimento. Diz que o homem é pela excelência da natureza humana "o intérprete da natureza inteira pela agudeza dos sentidos, pela inquirição da mente e pela luz do intelecto". ${ }^{8}$

Nos séculos XVII e XVIII, a concepção de dignidade da pessoa passa por um processo de laicização e racionalização, mantendo-se a noção da igualdade de todos em dignidade e liberdade. Destaca-se nesse período o nome de Immanuel Kant, cuja concepção de dignidade parte da autonomia ética do ser humano, além de sustentar que o ser humano não pode ser tratado como objeto, nem por si próprio.

Nas palavras de Jorge Miranda, compreender nos dias atuais o que é o princípio da dignidade da pessoa humana é ter como premissa que o ser humano, como fim de tudo, é um ente real, cujas necessidades mínimas concretas não podem estar sujeitas aos modelos abstratos tradicionais. Acentua que a dignidade é da pessoa concreta, em seu cotidiano, e não de um ser abstrato e que, em todo ser humano, estão presentes todas as faculdades da humanidade. ${ }^{9}$

A dignidade humana expressa um conjunto de valores incorporados ao patrimônio da humanidade. Seu conteúdo jurídico vem associado aos direitos fundamentais, envolvendo direitos individuais e sociais.

Luís Roberto Barroso ensina que o princípio da dignidade humana traz em si a integridade moral que deve ser assegurada a todas as pessoas por sua existência no mundo, relacionando-se tanto com a liberdade e os valores, quanto com as condições materiais de subsistência. Acentua ainda que "ele representa a superação da

\footnotetext{
${ }^{7}$ Ibidem, p. 16.

8 PICO DELLA MIRANDOLA, Giovanni. A dignidade do homem, 1999, p.49-53.

${ }^{9}$ MIRANDA, Jorge. Manual de direito constitucional, 1993, p. 169.
} 

aceitar o outro, o diferente, na plenitude de sua liberdade de ser, pensar e criar". ${ }^{10}$

Quanto ao seu núcleo material elementar, deve ser composta de um mínimo existencial. Entendido como bens e utilidades básicas para a subsistência física e indispensável ao desfrute da própria liberdade, não há dignidade, mesmo que haja sobrevivência, se esse núcleo elementar estiver aquém desse mínimo existencial. ${ }^{11}$

De acordo com Ingo Wolfgang Sarlet, esse princípio não contém apenas uma declaração ético e moral, mas constitui norma jurídica-positiva com status constitucional, a "qual se justifica plenamente sua caracterização como princípio constitucional de maior hierarquia axiológico-valorativa". ${ }^{12}$

Jorge Miranda relembra que "a Constituição, a despeito de seu caráter compromissário, confere unidade de direitos fundamentais que, por sua vez, repousa na dignidade da pessoa humana, isto é, na concepção que faz da pessoa fundamento e fim da sociedade e do Estado". ${ }^{13}$

A dignidade humana não é criação constitucional, ela é preexistente a todo conceito que se queira impor a sua existência. Entretanto, cada dignidade particular deve ser compreendida com relação às demais num todo social. Deve ser protegida pelo direito positivo, conferindo-lhe segurança jurídica. Reconhecendo a dignidade humana como fundamento em seu art. $1^{\circ}$, a República Federativa do Brasil transforma-a em um dos valores da ordem jurídica e a expande por todo o universo constitucional, servindo como critério interpretativo de todas as normas do ordenamento jurídico nacional.

No ordenamento anterior brasileiro importava o fortalecimento do Estado, pois os direitos fundamentais foram encarados como meras concessões das pessoas de Poder, que agiam de acordo com um juízo discricionário de Estados ditatoriais. Hoje, o enredo é outro. Agora é a pessoa quem deve ser fortalecida.

\section{A Incorporação dos Direitos Sociais na Cultura Constitucional Contemporânea}

A Revolução Francesa desencadeou, em curto espaço de tempo, a supressão das desigualdades entre indivíduos e grupos sociais, como a humanidade jamais

\footnotetext{
${ }^{10}$ BARROSO, Luís Roberto. Estudos de Direito Constitucional em homenagem a José Afonso da Silva: fundamentos Teóricos e Filosóficos do Novo Direito Constitucional Brasileiro, 2003, p. 51-52. ${ }^{11}$ Ibidem, p. 52-53.

${ }^{12}$ SARLET, Ingo Wolfgang. A eficácia dos Direitos Fundamentais, 2005, p. 221-222.

${ }^{13}$ MIRANDA, Jorge. Manual de Direito Constitucional, 1981, p. 180.
} 
tinha experimentado. Entretanto, percebe-se que o espírito da Revolução era muito mais a supressão das desigualdades estamentais do que a consagração das liberdades individuais para todos. ${ }^{14}$ Afirmando a igualdade jurídico-política dos cidadãos, a Revolução Francesa adotou o princípio do respeito absoluto à autonomia da vontade, deixando o Estado de intervir nas relações contratuais, o que culminou na exploração dos menos favorecidos.

Distingue-se nitidamente a Revolução Francesa da Americana. Esta, jamais conhecera as divisões estamentais ou as guerras de religião, que convulsionaram a Europa e deram ênfase às garantias judiciais. À exceção da escravidão, era juridicamente igualitária. Ao contrário, naquela o grande impulso revolucionário foi a eliminação das desigualdades, limitando-se a declarar direitos, sem mencionar os instrumentos judiciais que os garantissem..$^{15}$ Nesse particular, sabemos que, embora certos direitos subjetivos estejam desacompanhados de instrumentos assecuratórios, não deixam de ter sentido no meio social.

Após a luta pelos direitos individuais no século XVIII, surge no final do século XIX e início do século XX, uma consciência pelos direitos humanos sociais, a exemplo da luta sindical pela afirmação de direitos sociais.

A Carta Política mexicana de 1917 pontua Fábio Konder Comparato, "foi a primeira a atribuir aos direitos trabalhistas a qualidade de direitos fundamentais, juntamente com as liberdades e os direitos políticos (art. 5 e 123)." ${ }^{16}$ Acrescenta o autor que "a Constituição mexicana em relação ao sistema capitalista foi a primeira a estabelecer a desmercantilização do trabalho, ou seja, a proibição de equipará-lo a uma mercadoria qualquer, sujeita à lei da oferta e da procura no mercado". ${ }^{17}$

A Constituição Mexicana incorporou sentido diferente do que ocorria até então, de como seria tratada a relação contratual do trabalho entre trabalhadores e empresários. Com isso, criou-se a responsabilidade dos empregadores pelos acidentes de trabalho, pela relação contratual de trabalho evitando-se a sua exploração mercantil e evoluindo para o surgimento de um Estado Social de Direito. ${ }^{18}$ Constava na Constituição Mexicana a limitação da jornada de trabalho, a proteção à

\footnotetext{
${ }^{14}$ COMPARATO, Fábio Konder, A afirmação histórica dos Direitos Humanos, 2004, p.132.

${ }^{15}$ Ibidem, p. 135-136.

${ }^{16}$ Ibidem, p. 174. Arnaldo Süssekind, entretanto, acentua que foi a Constituição Suíça, aprovada em 1874 e emendada em 1896, a primeira constituição a inserir no seu texto direitos para os trabalhadores, sendo certo que a Constituição Francesa de 1848, apesar de curtíssima vigência, aludiu ao direito do trabalho, à educação profissional e a instituições de previdência. Direito Constitucional do Trabalho, 2004, p.13.

${ }^{17}$ Ibidem, p. 177.

${ }^{18}$ Ibidem, mesma página.
} 
maternidade, a idade mínima de admissão de empregados nas fábricas e o trabalho noturno dos menores na indústria. Entretanto, os direitos trabalhistas interessavam a uma pequena parcela da população, já que a economia da época era praticamente agrícola.

Apesar de sua breve vigência, a Constituição de Weimar aprimorou as linhas-mestras já traçadas pela Constituição Mexicana de 1917, com relação ao Estado da democracia social. Acrescentou à declaração de direitos e garantias individuais, instrumento de defesa contra o Estado, delimitações do campo bem demarcado da liberdade individual, que os Poderes Públicos não estavam autorizados a invadir: os direitos sociais. Esses, ao contrário dos direitos e das garantias individuais clássicos, têm por objeto não abstenção, mas atividade positiva do Estado, pois o direito à educação, à saúde, ao trabalho, à previdência social e a outros do mesmo gênero só se realizam por meio de políticas públicas, isto é, por programas de ação governamental. ${ }^{19}$ A democracia social representou, efetivamente até o final do século XX, a melhor defesa da dignidade humana ao complementar o direito civil, político, econômico e social. ${ }^{20}$

Com a eclosão das guerras mundiais na primeira metade do século XX, a dignidade da pessoa humana foi desvalorizada diante dos interesses das grandes potências. Passados esses acontecimentos, houve retomada da valorização dos direitos humanos na organização social dos Estados. Em 1944, a Conferência da OIT aprovou Declaração que, em seus cinco itens, dá ênfase à dignidade do ser humano, à liberdade de expressão e de associação, à formação profissional, ao direito de todos à educação, entre outros. ${ }^{21}$

Nesse sentido, Flávia Piovesan comenta que:

A Declaração Universal dos Direitos Humanos foi adotada em 10 de dezembro de 1948, pela aprovação unânime de 48 Estados, com 8 abstenções. A inexistência de qualquer questionamento ou reserva feita pelos Estados aos princípios da Declaração e a inexistência de qualquer voto contrário às suas disposições conferem à Declaração Universal o

\footnotetext{
${ }^{19}$ Ibidem, p.190. Realça ainda Comparato que “(...) foi, sem dúvida, pelo conjunto das disposições sobre a educação pública e o direito trabalhista que a Constituição de Weimar organizou as bases da democracia social. Consagrando a evolução ocorrida durante o século XIX, e que contribuiu decisivamente para a elevação social das camadas mais pobres da população em vários países da Europa Ocidental, atribui-se precipuamente ao Estado o dever fundamental de educação escolar. A educação fundamental foi estabelecida com a duração de oito anos, (...) A seção sobre a vida econômica abre-se com uma disposição de princípio, que estabelece como limite à liberdade de mercado a preservação de um nível de existência adequado à dignidade humana (art. 151) (..) Tal como na Constituição mexicana de 1917, os direitos trabalhistas e previdenciários são elevados ao nível constitucional de direitos fundamentais (art. 157 e ss.)".

${ }^{20}$ Ibidem, p. 189.

${ }^{21}$ SÜSSEKIND,Arnaldo, Convenções da OIT, 1944, p. 68-70.
} 

consolida a afirmação de uma ética universal, ao consagrar um consenso sobre valores de cunho universal a serem seguidos pelos Estados. ${ }^{22}$

Podemos dizer que nenhum documento no mundo é mais característico do caráter geral e amplo dos direitos fundamentais do que a Declaração Universal dos Direitos Humanos, proclamada no dia 10 de dezembro de 1948, a qual recebeu legitimidade de quase todas as nações. Norberto Bobbio ${ }^{23}$ acentua que a Declaração Universal dos Direitos do Homem, com relação ao processo de proteção global dos direitos do homem, é o ponto de partida para meta progressiva que representa, ao contrário, com relação aos direitos proclamados, o ponto de parada num processo que ainda está para ser concluído, pois os direitos elencados na Declaração não são os únicos e possíveis direitos do homem.

Promulgada a Declaração Universal, a humanidade passou a ter em mãos um documento para que todos os seres humanos estejam conscientes e lutem pela defesa de seus princípios, independentemente dos pontos de vista contraditórios ${ }^{24}$. A Declaração de 1948 introduz extraordinária inovação, quanto aos direitos até então inéditos. Propiciou avanço no sentido de maior liberdade da pessoa humana e despertou consciência mais clara desses direitos, além da disposição para defendêlos. Combinando o discurso liberal da cidadania com o discurso social, a Declaração passa a elencar tanto direitos civis e políticos (arts. $3^{\circ}$ a 21 ), quanto direitos sociais, econômicos e culturais (arts. 22 a 28), tornando-se a mais importante fonte dos direitos sociais consagrados pelas Constituições contemporâneas.

Acentua Norberto Bobbio que "a Declaração representa a consciência histórica que a humanidade tem dos próprios valores fundamentais na segunda metade do século XX. É uma síntese do passado e uma inspiração para o futuro: mas suas tábuas não foram gravadas de uma vez para sempre". ${ }^{25}$

$\mathrm{Na}$ visão de Vicente de Paulo Barretto, os direitos humanos situam-se, em razão de suas características morais, além e acima da organização estatal, com raízes, em última instância, na consciência ética coletiva. Assevera que, in verbis:

A investigação sobre a natureza dos direitos humanos tem a ver com a busca dos modelos racionais e lógicos, que deitam as suas raízes na

\footnotetext{
${ }^{22}$ PIOVESAN, Flávia. Direitos Humanos e o Direito Constitucional Internacional, 1996, p. 155156.

${ }^{23}$ BOBBIO, Norberto. A Era dos Direitos, 1992, p. 33.

${ }^{24}$ BARCELLOS, Fernando de Almeida. Teoria Geral dos Direitos Humanos, 1996, p.111.

${ }^{25}$ BOBBIO, Norberto. A Era dos Direitos, 1992, p.34. O autor entende que se está diante não só do problema da garantia daqueles direitos, mas também de aperfeiçoa-los e não deixa-los enrijecer-se em fórmulas vazias.
} 
construção historicamente verificável de que esses direitos visam à proteção de bens e valores que, no seu todo, constituem o cerne da dignidade humana e que foram sendo construídos no espaço público da sociedade democrática nos últimos dois séculos. ${ }^{26}$

Os direitos sociais vêm, aos poucos, sendo incorporados na cultura Constitucional Contemporânea. Foi o que aconteceu, por exemplo, na Conferência das Nações Unidas, reunidas em Istambul, de 3 a 14 de junho de 1996, que tratou dos assentamentos humanos, reafirmando como objetivos universais a garantia de habitação adequada para todos. Essa Declaração afirmou que efetivar direitos humanos de conteúdos econômicos, sociais e culturais requer infra-estrutura adequada, no tocante a serviços públicos de saneamento e transporte, o respeito constante aos ecossistemas, bem como a aplicação das oportunidades de emprego. ${ }^{27}$

Há, sem dúvida, uma interdependência desses fatores, por isso, os direitos econômicos, sociais e culturais, devem ser vinculados à ação estatal, caso contrário, serão apenas meros programas.

\section{Direitos Fundamentais e sua classificação}

No tocante à classificação desses direitos, o constitucionalista José Joaquim Gomes Canotilho preleciona que hoje os autores preferem falar em dimensões de direitos a gerações, pois a palavra "geração" traz a idéia de perda de relevância e até de substituição de direitos, o que não é correta. Ensina que os direitos são de todas as gerações. ${ }^{28}$

Os direitos fundamentais da primeira dimensão encontram suas raízes especialmente na doutrina iluminista e jusnaturalista dos séculos XVII e XVIII (Hobbes, Locke, Rousseau e Kant). Sua finalidade consiste, principalmente, na realização da liberdade do indivíduo frente ao poder do Estado - direitos civis e políticos -, ou seja, o Estado permaneceria inerte diante desses direitos de cunho individualista. Esses direitos foram conquistados pelas revoluções políticas do final do século XVIII, que marcaram o início da positivação das reivindicações burguesas nas primeiras constituições escritas do mundo ocidental.

São, portanto, apresentados como direitos de cunho "negativo", uma vez que dirigidos a uma abstenção e não a uma conduta positiva por parte dos poderes

\footnotetext{
${ }^{26}$ BARRETTO, Vicente de Paulo. Reflexões sobre os Direitos Sociais, 2003, p.23.

${ }^{27}$ Ibidem, p.23-24.

${ }^{28}$ CANOTILHO, José Joaquim Gomes. Direito Constitucional e Teoria da Constituição, p. 384. 
públicos, sendo, neste sentido, "direitos de resistência ou de oposição perante o Estado". ${ }^{29}$ Assumem particular relevo, no rol desses direitos, os direitos à vida, à liberdade, à propriedade e à igualdade perante a lei, ou seja, direitos civis e políticos.

Nas Constituições Brasileiras, a primeira a elencar um rol de direitos individuais foi a Constituição do Império (1824), aliás, como afirma José Afonso da Silva $a^{30}$, foi a primeira constituição no mundo a objetivar e a positivar os direitos do homem dando-lhes efetividade antes mesmo da Constituição da Bélgica de 1831.

Desde então, nossas Constituições asseguram aos brasileiros e aos estrangeiros residentes no país a inviolabilidade dos direitos concernentes à liberdade, à propriedade e à segurança, entre outros direitos que foram sendo acrescentados no decorrer dos tempos.

Também chamados de direitos fundamentais de defesa pela maioria da doutrina nacional, dirigem-se a uma obrigação de abstenção por parte dos poderes públicos, implicando dever de respeito a determinados interesses individuais. Esta função defensiva dos direitos fundamentais não implica, na verdade, a exclusão total do Estado, mas a limitação de sua intervenção em determinadas condições de natureza material e procedimental e em conformidade com a Constituição. ${ }^{31}$

Positivados constitucionalmente no século XX, mas com histórias de lutas que remontam ao século XIX (Marx; Engels), os direitos de segunda dimensão vêm complementar um leque de liberdades, incluindo as assim denominadas liberdades de expressão coletiva (liberdade de expressão, imprensa, manifestação, reunião, associação) e os direitos de participação política, tais como o direito de voto e a capacidade eleitoral. Também algumas garantias processuais (devido processo legal, habeas corpus, direito de petição) enquadram-se nesta categoria, além da igualdade formal perante a lei.

Foi no século XX que esses novos direitos fundamentais, ditos de segunda dimensão, acabaram sendo consagrados em um número significativo de constituições, principalmente nas constituições do segundo pós-guerra, e também foram objetos de vários tratados internacionais. Embora já tenham surgido há algumas décadas, ainda não têm a sua merecida tutela. Valle Labrada Rubio assevera

\footnotetext{
${ }^{29}$ BONAVIDES, Paulo. Curso de Direito Constitucional, 2004, p. 564. Pontua ainda que: "Entram na categoria do status negativus da classificação de Jellinek e fazem também ressaltar na ordem dos valores políticos a nítida separação entre a Sociedade e o Estado. Sem o reconhecimento dessa separação, não se pode aquilatar o verdadeiro caráter antiestatal dos direitos da liberdade, conforme tem sido professado com tanto desvelo teórico pelas correntes do pensamento liberal de teor clássico".

${ }^{30}$ SILVA, José Afonso. Curso de Direito Constitucional Positivo, 2004, p. 170.

${ }^{31}$ SARLET, Ingo Wolfgang. A eficácia dos Direitos Fundamentais, 2005, p. 186.
} 
que "são muitos os autores e as correntes doutrinárias que reclamam a proteção dos direitos da classe trabalhadora. Destaca-se neste sentido a influência do Manifesto Comunista de 1848, enquanto à conscientização da classe obreira.". ${ }^{32}$ Em nosso cenário os direitos de segunda dimensão encontram-se em estágio de concretização envoltos em problemas econômicos, políticos, culturais. Embora reconhecidos e garantidos, permanecem sem a efetividade essencial merecida, levando milhares de pessoas a viverem sem condições mínimas de dignidade.

Como oportunamente observa Paulo Bonavides ${ }^{33}$, esses direitos fundamentais "nascem abraçados ao princípio da igualdade, do qual não se podem separar", mas com eficácia duvidosa, "em virtude de sua própria natureza de direitos que exigem do Estado determinadas prestações materiais", diferentemente dos clássicos direitos de liberdade e de igualdade formal.

Ensina Willis Santiago Guerra Filho que os direitos de segunda dimensão, in verbis:

\begin{abstract}
são aqueles consagrados a partir do momento em que surgem reclamos da realização, pelo Estado, de maior justiça social, promovendo uma situação mais igualitária entre indivíduos e setores da sociedade economicamente desnivelados. Esses seriam, portanto, direitos a determinadas prestações do Estado ao povo que o compõe, Leistungsrechte, típicos do Estado social. ${ }^{34}$
\end{abstract}

Esse novo sentido do princípio da igualdade seguiu para um contexto em que se garantissem aos indivíduos certas prestações sociais estatais, como a assistência social, a saúde, a educação, transportando-se de uma situação formal para uma concreta, dentro dos obstáculos econômicos.

Para Celso Lafer, os problemas práticos da tutela surgem em primeiro lugar com relação aos direitos de primeira dimensão,sendo o caso dos limites eventualmente impostos ao direito de reunião, de associação e de opinião. Mas, em relação aos direitos de segunda dimensão, esses problemas também surgem, no momento em que, por meio do Estado enquanto sujeito passivo, são estabelecidas as prioridades para saldar compromissos assumidos em relação aos indivíduos, no campo da saúde, da educação ou do trabalho. ${ }^{35}$

\footnotetext{
${ }^{32}$ LABRADA RUBIO, Valle. Introducción a la Teoria de los Derechos Humanos Fundamento. Historia. Declaración Universal de 10 de diciembre de 1948, 1998, p. 123.

${ }^{33}$ BONAVIDES, Paulo. Curso de Direito Constitucional, 2004, p. 564.

${ }^{34}$ GUERRA FILHO, Willis Santiago. Processo Constitucional e Direitos Fundamentais, 2005, p. 165.

${ }^{35}$ LAFER, Celso. A Reconstrução dos Direitos Humanos, 1988, p.128. 
A palavra "social" traz referência ao princípio da justiça social, correspondendo às classes menos favorecidas de cunho trabalhista, em virtude das desigualdades que ainda persistem. Os direitos sociais também se referem aos indivíduos, como os de primeira dimensão, mas de um modo relacionado com a justiça social. ${ }^{36}$

Os direitos fundamentais a prestações enquadram-se no âmbito dos direitos de segunda dimensão, correspondendo a uma posição ativa do Estado. No plano do direito positivo, o reconhecimento da importância dos direitos de segunda dimensão já se encontrava na Constituição Francesa de 1791. Previa, por meio de uma instituição, cuidados às crianças abandonadas, alívio aos pobres doentes e oferta de trabalho para os pobres inválidos que não o encontrassem. ${ }^{37}$

Foi a Constituição Brasileira de 1934 que inaugurou o constitucionalismo social no Brasil, inspirada nas Constituições do México e de Weimar.

$\mathrm{Na}$ Constituição brasileira vigente, há um capítulo especial dedicado aos Direitos Sociais, inserido no catálogo dos Direitos e Garantias Fundamentais. $\mathrm{O}$ artigo $6^{\circ}$ relaciona uma série de direitos que o Estado assume como deveres de proteção, mas cuja efetividade permanece restrita a diferentes alternativas e a limitações dos meios disponíveis. Os conteúdos do artigo $6^{\circ}$ constituem verdadeiros direitos frente ao Estado. São direitos sociais necessários para manter-se vida digna, sem os quais, a vida seria levada a condições penosas que resultam em degradação da sociedade por meio de violências.

Os direitos sociais descritos na Carta Magna são mais que direitos exercitáveis pelos cidadãos, são exigências que não podem ser adiadas, nem direcionadas à realização social, cuja efetividade se dá a toda a coletividade e não exclusivamente a um indivíduo.

Celso Lafer comenta que, in verbis:

A primeira geração de direitos viu-se igualmente complementada historicamente pelo legado do socialismo, vale dizer, pelas reivindicações dos desprivilegiados a um direito de participar do "bem-estar social", entendido como bens que os homens, através de um processo coletivo, vão acumulando no tempo. (...) Tais direitos - como ao trabalho, à saúde, à educação - têm como sujeito passivo o Estado. (...) O titular desse direito, no entanto, continua sendo, como nos direitos de primeira geração, o homem na sua individualidade.. ${ }^{38}$

\footnotetext{
${ }^{36}$ SARLET, Ingo Wolfgang. A eficácia dos direitos fundamentais, 2005, p. 56.

${ }^{37}$ LAFER, Celso. A Reconstrução dos Direitos Humanos, 1988, p.128.

${ }^{38}$ Ibidem, p. 127.
} 
Daí a complementaridade, na perspectiva ex parte populi, entre os direitos de primeira e de segunda geração, pois estes últimos buscam assegurar as condições para o pleno exercício dos primeiros, eliminando ou atenuando os impedimentos ao pleno uso das capacidades humanas. Por isso, os direitos de crédito, denominados direitos econômico-sociais e culturais, podem ser encarados como direitos que tornam reais direitos formais: procuram garantir a todos o acesso aos meios de vida e de trabalho num sentido amplo, impedindo, desta maneira, a invasão do todo em relação ao indivíduo, que também resulta da escassez dos meios de vida e de trabalho. ${ }^{39}$

Nesse sentido, tem-se que os direitos individuais estão relacionados aos direitos sociais, na medida em que a eficácia daqueles é sustentada e incorporada pela sociedade. Há uma intersubjetividade entre essas dimensões de direitos fundamentais.

Dentro dos direitos de segunda dimensão há que observar que existem outros direitos além dos denominados de cunho positivo (prestacional). A doutrina os chama de 'liberdades sociais', do que dão conta os exemplos de liberdade de sindicalização, do direito de greve, da proibição de discriminações, bem como o reconhecimento dos direitos dos trabalhadores. ${ }^{40}$

José Afonso da Silva aduz que o "núcleo central dos direitos sociais é constituído pelo direito do trabalho (conjunto de direitos dos trabalhadores) e pelo direito de seguridade social". Em torno dela, diz o autor, gravitam outros direitos sociais, como o direito à saúde, o direito à previdência social, assistência social, à educação, ao meio ambiente sadio. ${ }^{41}$

Os direitos à educação, à saúde e à assistência, enfim a todos os considerados direitos sociais, não deixam de ser direitos fundamentais pelo fato de não serem criadas as condições materiais e institucionais necessárias a sua fruição. Esses direitos necessitam de ações que os efetivem e o texto garante a todos tais direitos ao atribuir ao Estado o dever de prestá-los. Nesse sentido, a efetividade dos direitos sociais ocorre por meio de implementação de políticas públicas que proporcionem a fruição desses direitos fundamentais.

\footnotetext{
${ }^{39}$ Ibidem, p. 127-128.

${ }^{40}$ SARLET, Ingo Wolfgang. A eficácia dos direitos fundamentais, 2005, p.56. Como exemplo de direitos dos trabalhadores citamos o direito a férias, ao repouso semanal remunerado e à limitação da jornada de trabalho.

${ }^{41}$ SILVA, José Afonso. Curso de direito constitucional positivo, 2004, p. 464. 
Os direitos reconhecidos como do homem na sua singularidade, sejam eles de primeira ou de segunda dimensão, têm titularidade, não no sentido processual, inequívoca: o indivíduo. $\mathrm{O}$ mesmo já não ocorre com os direitos de terceira e de quarta dimensões que têm como titulares grupos humanos como a família, o povo, as coletividades étnicas e a própria humanidade, mas que no fundo levam ao bemestar da pessoa em sua individualidade.

Têm sido contemporaneamente denominados direitos de terceira dimensão os direitos de fraternidade ou de solidariedade, que impõem a defesa da espécie humana. Os direitos de terceira dimensão têm se desenvolvido no plano internacional sob o impulso de organizações internacionais e, especialmente, por intermédio das Nações Unidas. Fazem surgir reflexões sobre o desenvolvimento, a paz, o meio ambiente e sobre o patrimônio comum da humanidade.

Esses direitos têm como titular não o indivíduo em sua singularidade, mas sim os grupos humanos como família, povo, nação, coletividades regionais ou étnicas e a própria humanidade. ${ }^{42}$ Celso Lafer ensina que "o caso por excelência é o do direito à autodeterminação dos povos, expresso na Carta das Nações Unidas (art. $1^{\circ}$., $\int$ 20., art, 55) e reivindicado com muita nitidez na prática da ONU em relação às potências colonialistas no processo de descolonização, a partir de 1514(XV) da Assembléia de 14 de dezembro de 1960". ${ }^{43}$

Paulo Bonavides discorre que "dotados de altíssimo teor de humanismo e universalidade, os direitos da terceira dimensão tendem a cristalizar-se no fim do século XX, enquanto direitos que não se destinam especificamente à proteção dos interesses de um indivíduo, de um grupo ou de um determinado Estado". ${ }^{44}$

Dentre os direitos de terceira dimensão, o direito ao meio ambiente é o que mais bem tem-se estabelecido, tanto no âmbito interno quanto internacionalmente. Nossa Carta Magna, principalmente no artigo 225, disciplinou que "todos têm direito ao meio ambiente ecologicamente equilibrado, bem de uso comum do povo e essencial à sadia qualidade de vida, impondo-se ao Poder Público e à coletividade o dever de defendê-lo e preservá-lo para as presentes e futuras gerações”. Constatase, assim, que no direito interno, vem-se firmando e desenvolvendo cada vez mais o direito do homem a um meio ambiente equilibrado.

\footnotetext{
${ }^{42}$ LAFER, Celso. A reconstrução dos direitos humanos, 1988, p. 131.

${ }^{43}$ Idem, mesma página.

${ }^{44}$ BONAVIDES, Paulo. Curso de direito constitucional, 2004, p. 569. Acentua ainda que têm primeiro por destinatário o gênero humano, num momento expressivo de sua afirmação com valor supremo em termos de existencialidade concreta.
} 
Conclui-se da doutrina exposta que no direito de terceira dimensão concebemse direitos cujos sujeitos não são mais individuais ou coletivos, mas sim o gênero humano, decorrentes de uma nova conjuntura política, econômica e social voltada para as relações entre as nações.

Os direitos de quarta dimensão ainda não estão totalmente claros. O constitucionalista Paulo Bonavides refere-se a eles, sustentando que esses direitos fundamentais se globalizaram e que isso corresponde à universalização no campo institucional, equivalendo à derradeira fase de institucionalização do Estado Social. ${ }^{45}$

A quarta dimensão dos direitos fundamentais é composta pelos direitos à democracia (direta), à informação e o direito ao pluralismo. Assevera Paulo Bonavides que "deles depende a concretização da sociedade aberta do futuro, em sua dimensão de máxima universalidade, para a qual parece o mundo inclinar-se no plano de todas as relações de convivência". ${ }^{46}$

Conclui ainda que, in verbis:

$$
\begin{aligned}
& \text { a nova universalidade procura, enfim, subjetivar de forma concreta e } \\
& \text { positiva os direitos da tríplice geração na titularidade de um indivíduo } \\
& \text { que antes de ser o homem deste ou daquele País, de uma sociedade } \\
& \text { desenvolvida ou subdesenvolvida, é pela sua condição de pessoa um } \\
& \text { ente qualificado por sua pertinência ao gênero humano, objeto daquela } \\
& \text { universalidade. }{ }^{47}
\end{aligned}
$$

Valle Labrada Rubio aduz que os direitos de quarta dimensão são "todos aqueles direitos humanos que vão surgindo como resultado do desenvolvimento da técnica e as conseqüências desse desenvolvimento". 48

\section{Os direitos fundamentais sociais na Constituição brasileira de 1988}

Após longo período de regime militar ditatorial, que perdurou de 1964 a 1985, desencadeou-se no Brasil o processo de democratização, que culminou com a promulgação da Constituição de 1988, chamada de Constituição- cidadã, assim chamada porque houve ampla participação popular e, especialmente, devido aos largos espaços destinados ao tratamento dos direitos e das garantias fundamentais, necessários ao desenvolvimento da cidadania.

${ }^{45}$ Ibidem, p. 571.

${ }^{46}$ Ibidem, mesma página.

${ }^{47}$ Ibidem, p.574.

${ }^{48}$ LABRADA RUBIO, Valle. Introducción a la Teoria de los Derechos Humanos: Fundamento. Historia. Declaración Universal de 10 de diciembre de 1948, 1998, p. 124. 
A Constituição de 1988 incorporou vários direitos relacionados aos empregados domésticos e em relação aos outros direitos sociais, buscando a igualdade material. Mas engana-se quem pensa que foi pacificamente. Houve muita luta e determinação do povo brasileiro, e naturalmente dos Constituintes, para que esses direitos fossem incorporados à Nova Constituição.

Apesar de todos os empecilhos pelos quais a Assembléia Constituinte passou, a Nova Carta incorporou significativos avanços no campo dos direitos humanos, tanto os individuais como os difusos e coletivos, trazendo, também, diversos remédios constitucionais para garantir a eficácia desses direitos. Previu, também, os direitos sociais, que reconheceram os direitos dos cidadãos de terem atividade positiva do Estado, como por exemplo, o seguro-desemprego, a proteção contra a dispensa imotivada, e o salário mínimo.

Buscando promover a igualdade material, a Constituição de 1988 traz um Capítulo próprio (Capítulo I), dedicado aos direitos sociais, encartado no Título II - Dos Direitos e Garantias Fundamentais, trazendo, ainda, um título especial sobre a Ordem Social. Mas antes a Constituição define princípios fundamentais, como, por exemplo, valores sociais do trabalho e livre iniciativa. Estabelece, também, objetivos fundamentais para a República, como o desenvolvimento nacional, a erradicação da pobreza e da marginalização e a redução das desigualdades sociais e regionais.

Na definição de José Afonso da Silva, os direitos sociais, como dimensão dos diretos fundamentais do homem, são

\begin{abstract}
prestações positivas estatais, enunciadas em normas constitucionais, que possibilitam melhores condições de vida aos mais fracos, direitos que tendem a realizar a igualização de situações desiguais. Valem como pressupostos de gozo dos direitos individuais na medida em que criam condições materiais mais propícias ao auferimento da igualdade real, o que, por sua vez, proporciona condição mais compatível com o exercício efetivo da liberdade. ${ }^{49}$
\end{abstract}

Os direitos sociais são endereçados ao Estado, para o qual surgem, na maioria das vezes, certos deveres de prestações positivas visando à melhoria das condições de vida. Com base nos arts. $6^{\circ}$. a $11^{\circ}$. da Constituição, José Afonso da Silva agrupou os direitos sociais, sem a preocupação com classificação rígida, em cinco classes: a) direitos sociais relativos ao trabalhador; b) direitos sociais relativos à seguridade, compreendendo os direitos à saúde, à previdência e à assistência social; c) direitos

\footnotetext{
${ }^{49}$ SILVA, José Afonso. Poder Constituinte e Poder Popular, 2002, p. 199. 
sociais relativos à educação e à cultura; d) direitos sociais relativos à família, à criança, ao adolescente e ao idoso; e) direitos sociais relativos ao meio ambiente. ${ }^{50}$

A Carta de 1988, em seu artigo $6^{\circ}$, disciplinou o direito à educação, à saúde, ao trabalho, ao lazer, à previdência social, à proteção à maternidade e à infância, à assistência aos desamparados. Acrescentado pela Emenda Constitucional n 26 de 14/02/2000, o direito à moradia passou a fazer parte do rol dos direitos sociais consagrados no artigo $6^{\circ}$.

No artigo $7^{\circ}$ declinou direitos especificamente em favor dos trabalhadores; entre outros, o seguro-desemprego, o fundo de garantia por tempo de serviço, o piso salarial, o décimo terceiro salário, a participação nos lucros, o repouso semanal remunerado, o reconhecimento das convenções e de acordos coletivos de trabalho.

Além dos direitos sociais previstos no Capítulo II do Título I, outros direitos sociais encontram-se disciplinados também no Título VIII - Da Ordem Social. Na Constituição de 1988, os direitos sociais estão dispostos separadamente do Título VII - Da Ordem Econômica e Financeira, rompendo a tradição constitucional brasileira que, desde 1934, os elencava juntamente com os direitos disciplinados na ordem econômica. ${ }^{51}$

Infere-se que a Constituição de 1988 é, basicamente, em muitas de suas dimensões essenciais, uma Constituição do Estado Social. Paulo Bonavides assevera que "O verdadeiro problema do Direito Constitucional de nossa época está em como juridicizar o Estado Social, como estabelecer e inaugurar novas técnicas ou institutos processuais para garantir os direitos sociais básicos, a fim de fazê-los efetivos". ${ }^{52}$

É certo que muito avançou a Carta Magna de 1988, com o mandado de injunção, o mandado de segurança coletivo, e a ação de inconstitucionalidade por omissão. Entretanto, como acentua Bonavides, até onde irão na prática essas garantias? Até onde haverá condições materiais propícias para traduzir em realidade o programa de direitos básicos formalmente postos na Constituição? O próprio autor responde que é muito cedo para antecipar conclusões, mas já se intui que pela precariedade dos recursos e pela latitude daqueles direitos, está emergindo uma crise, a crise constituinte do Estado e da Sociedade brasileiros. ${ }^{53}$

\footnotetext{
${ }^{50}$ Ibidem, mesma página.

${ }^{51}$ SÜSSEKIND, Arnaldo. Direito Constitucional do Trabalho, 2004, p. 18. Entende o autor que essa separação "é desaconselhável pelo entrelaçamento existente entre os direitos social-trabalhistas e a ordem econômica, porque possuem alguns princípios comuns e devem seguir a diretriz segundo a qual a finalidade do desenvolvimento econômico há de ser o processo social”.'Cita a Declaração de 1944 e 1948 como sucedâneo ao seu entendimento.

${ }^{52}$ BONAVIDES, Paulo. Curso de Direito Constitucional, 2004, p. 373.

${ }^{53}$ Ibidem, mesma página.
} 
Os direitos sociais constituem direitos fundamentais e a Constituição de 1988 assumiu, em sua essência, essa posição, considerando-os como valores sociais. São compreendidos como autênticos direitos subjetivos inerentes ao espaço existencial do cidadão, independentemente da sua exeqüibilidade imediata. Sendo assim, com a mesma dignidade subjetiva dos direitos, das liberdades e das garantias devem ser tomados o direito à saúde, à educação, à habitação, o direito à segurança social. ${ }^{54}$

Os direitos fundamentais sociais, na medida em que dispostos no art. $6^{\circ}$, da Constituição Federal, trazem conteúdos para a dignidade da pessoa humana e devem ser protegidos e efetivados. Norberto Bobbio, ensina que, in verbis:

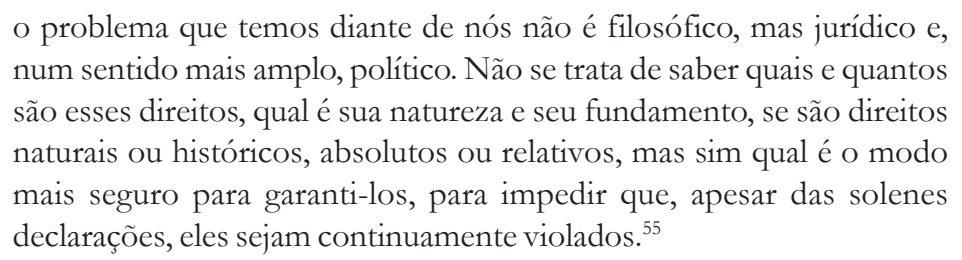
num sentido mais amplo, político. Não se trata de saber quais e quantos são esses direitos, qual é sua natureza e seu fundamento, se são direitos naturais ou históricos, absolutos ou relativos, mas sim qual é o modo mais seguro para garanti-los, para impedir que, apesar das solenes declarações, eles sejam continuamente violados. ${ }^{55}$

Esses direitos são necessidades humanas fundamentais e seu conteúdo constante do art. $6^{\circ}$ de nossa Carta Magna não é programa de orientação a ser seguido pelo Poder Legislativo e pelo executivo, mas sim, constitui-se verdadeira exigência dos cidadãos frente ao Estado, pois saúde, educação, moradia, previdência e segurança social, entre outras, são essenciais a uma vida digna.

\section{Considerações finais}

A Constituição Federal do Brasil, promulgada em 1988, marcou o fim do período de transição, inaugurando o período de consolidação da democracia e representando um avanço em relação aos direitos individuais e sociais para a sociedade brasileira. Como Estado Democrático de Direito, o Estado brasileiro deve tornar-se instrumento a serviço da coletividade, respeitando e proporcionando condições para o exercício dos direitos humanos.

A evolução histórica dos direitos fundamentais mostrou a incorporação dos direitos sociais nas Constituições Contemporâneas e em nossa Carta Magna de 1988, esta, que muito avançou positivando os direitos sociais, por sua relevância no contexto constitucional brasileiro, direitos esses que compõem matéria que busca promover a igualdade material.

\footnotetext{
${ }^{54}$ PEREZ LUÑO, Antonio Enrique. Derechos Humanos, 1995, p.472.

${ }^{55}$ Ibidem, p. 218.
} 

englobar de forma concreta e positiva as três dimensões de direitos. Embora as quatro dimensões tratem dos direitos fundamentais, cada qual com suas particularidades, é certo que todas têm como base o bem estar da pessoa em sua individualidade, e é por ela - a pessoa - que todos esses direitos devem, democraticamente, ser respeitados.

\section{$7 \quad$ Referências}

BARCELLOS, Fernando de Almeida. Teoria geral dos direitos humanos. Porto Alegre: Sergio Antônio Fabris, 1996.

BARRETO, Vicente de Paulo. Reflexões sobre os direitos sociais. In: Boletim de Ciências Econômicas. Coimbra, 2003.

BARROSO, Luís Roberto. Estudos de direito constitucional em homenagem a José Afonso da Silva: fundamentos teóricos e filosóficos do novo direito constitucional brasileiro. Coordenadores: Eros Roberto Grau e Sérgio Sérvulo da Cunha. São Paulo: Malheiros, 2003.

BOBBIO, Norberto. A era dos direitos. Tradução de Carlos Nelson Coutinho. Rio de Janeiro: Campus, 1992.

BONAVIDES, Paulo. Curso de direito constitucional. 15. ed. atual. São Paulo: Malheiros, 2004.

CANOTILHO, José Joaquim Gomes. Direito constitucional e teoria do direito. 5. ed. Coimbra: Almedina.

COMPARATO. Fábio Konder. A afirmação histórica dos direitos humanos. 3. ed. rev. amp. São Paulo: Saraiva, 2004.

CONSTITUIÇÃO DA REPÚBLICA FEDERATIVA DO BRASIL. 35. ed. atual. amp., 2005.

DALLARI, Dalmo de Abreu. Direitos humanos e cidadania. São Paulo: Moderna, 1982.

Elementos de teoria geral do estado. 24. ed. São Paulo: Saraiva, 2003. FERREIRA FILHO, Manoel Gonçalves. Poder constituinte e direito adquirido. Revista de Direito Administrativo, n. 210, Rio de Janeiro, Renovar, 1997.

Comentários à constituição brasileira de 1988: arts. 1. a 103. 3.ed. atual. São Paulo: Saraiva, 2000, v.1.

DECLARAÇÃO UNIVERSAL DA ONU (1948).

GUERRA FILHO, Willis Santiago. Processo constitucional e direitos fundamentais. 4. ed. rev. e amp. São Paulo: RCS, 2005. 
LAFER, Celso. A reconstrução dos direitos humanos: um diálogo com o pensamento de Hannah Arendt. 2. ed. São Paulo: Companhia das Letras, 1988.

MIRANDA, Jorge. Manual de direito constitucional. Coimbra: Coimbra Editora, vol II, 1981.

IV, 1993.

Manual de direito constitucional. 3. ed. Coimbra: Coimbra Editora, vol

PEREZ LUÑO, Antonio-Enrique. Derechos humanos, estado de derecho y constitución. 5. ed. Madrid: Tecno, 1995.

PICO DELLA MIRANDOLA, Giovanni. A dignidade do homem. Tradução de Luiz Feracine. 2. ed. Mato Grosso do Sul: Uniderp, 1999.

PIOVESAN, Flávia. Direitos humanos e o direito constitucional internacional. São Paulo: Max Limonad, 1996.

LABRADA RUBIO, Valle. Introducción a la teoria de los derechos humanos: Fundamento. Historia. Declaracion Universal de 10 de Diciembre de 1948. Editoral Civitas, 1998.

SARLET, Ingo Wolfgang. A eficácia dos direitos fundamentais. 5. ed. São Paulo: Livraria do Advogado, 2005.

SILVA, José Afonso da. Curso de direito constitucional positivo. 23. ed. São Paulo: Malheiros, 2004.

Poder constituinte e poder popular. São Paulo: Malheiros, 2002.

SÜSSEKIND, Arnaldo. Direito constitucional do trabalho. 3. ed. São Paulo: Renovar, 2004.

. Convenções da OIT. São Paulo: Ltr, 1944. 